Article

\title{
Investigation of Microstructure of Al-5Ti-0.62C System and Synthesis Mechanism of TiC
}

\author{
Wanwu Ding $1,2, *\left(\mathbb{0}\right.$, Taili Chen ${ }^{1,2}$, Xiaoyan Zhao ${ }^{1,2}$, Yan Cheng ${ }^{1,2}$, Xiaoxiong Liu ${ }^{1,2}$ and \\ Lumin Gou ${ }^{1,2}$ \\ 1 State Key Laboratory of Advanced Processing and Recycling of Nonferrous Metals, Lanzhou University of \\ Technology, Lanzhou 730050, China; chen_taili@163.com (T.C.); zxyxmy@163.com (X.Z.); \\ chengyanLUT@163.com (Y.C.); 1xxlbj@163.com (X.L.); goulumin@163.com (L.G.) \\ 2 School of Materials Science and Engineering, Lanzhou University of Technology, Lanzhou 730050, China \\ * Correspondence: dingww@lut.cn; Tel.: +86-1511-7183-365
}

Received: 2 December 2019; Accepted: 7 January 2020; Published: 9 January 2020

\begin{abstract}
Al-Ti-C master alloys have been widely investigated by various researchers. However, their refining effectiveness is still severely compromised by the preparation process. In this work, the aluminum melt in-situ reaction was carried out to synthesize the Al-5Ti-0.62C, and its refining performance was estimated. The thermodynamics calculation and differential scanning calorimeter experiment were used to investigate the synthesis mechanism of TiC. Quenching experiment was conducted to explore phase and microstructure transformation of the Al-5Ti-0.62C system. The results show that the main phases of $\mathrm{Al}-5 \mathrm{Ti}-0.62 \mathrm{C}$ master alloys are $\alpha-\mathrm{Al}_{1} \mathrm{Al}_{3} \mathrm{Ti}$, and $\mathrm{TiC}$ and it has a positive effect on commercial pure aluminum refining. Commercial pure aluminum is completely refined into the fine equiaxed structure by adding $0.3 \% \mathrm{Al}-5 \mathrm{Ti}-0.62 \mathrm{C}$ master alloy. TiC particles mainly distribute in the grain interior and grain boundaries. The excess $\mathrm{Ti}$ came from the dissolution of $\mathrm{Al}_{3}$ Ti spreading around $\mathrm{TiC}$ and finally forming the Ti-rich zone to promote the nucleation of $\alpha$-Al. The experiments certified that $\mathrm{TiC}$ was formed by the reaction between solid $\mathrm{C}$ and excess $\mathrm{Ti}$ atoms. The main reactions in the $\mathrm{Al}-5 \mathrm{Ti}-0.62 \mathrm{C}$ system were that solid $\mathrm{Al}$ is transferred into liquid $\mathrm{Al}$, and then liquid $\mathrm{Al}$ reacted with solid $\mathrm{Ti}$ to form the $\mathrm{Al}_{3} \mathrm{Ti}$. At last, the release of a lot of heat promotes the formation of $\mathrm{TiC}$ which formed by the Ti atoms and solid C.
\end{abstract}

Keywords: Al-5Ti-0.62C master alloy; quenching experiment; grain refining; differential scanning calorimeter

\section{Introduction}

Aluminum and its alloys have been widely used in military, aerospace, building, packaging, and electronics industries due to their excellent wear and corrosion resistance, low density, good high strength, high specific strength, and low efficiency of thermal expansion [1-3].

Nowadays, with the development of the industry, it is urgent to improve multi-properties for aluminum alloys $[4,5]$. Numerous studies have showed that the grain refining plays an important role in improving the properties of aluminum alloys [6-8]. Since Cibula [9] proposed the Carbide boride theory, tremendous efforts have been devoted to investigating the grain refining for aluminum alloy, including Al-Ti, Al-B, Al-C, Al-P, Al-Ti-B, Al-Ti-B-C, and Al-Ti-C master alloys [5,10-12]. Among which, $\mathrm{Al}-\mathrm{Ti}-\mathrm{B}$ and Al-Ti-C master alloys have been extensively studied at present. Furthermore, as an alternative grain refiner for Al-Ti-B master alloys, Al-Ti-C master alloys have the advantages of resistance to $\mathrm{Zr}$ poisoning and low aggregation tendency of $\mathrm{TiC}$ in aluminum melt [13-16]. Therefore, some works have been undertaken to investigate the influence of prepared processing parameters on phase synthesis and refinement performance of Al-Ti-C master alloys. Liu et al. $[17,18]$ studied the effects of temperature and 
holding time on the microstructure of Al-Ti-C alloys. Yang et al. [19] and Gezer et al. [20] discussed the influence of the Ti/C stoichiometry on the grain refining performance of Al-Ti-C master alloys. Svynarenko et al. [21] investigated the importance of excess Ti for the refining efficiency of Al-Ti-C master alloy. Moreover, the in situ synthesis process of Al-Ti-C master alloys in aluminum melt by thermodynamic calculations and differential scanning calorimeter (DSC) experiment were analyzed [22-25]. It is considered that after the reaction of $\mathrm{Ti}$ with $\mathrm{Al}$ to form $\mathrm{Al}_{3} \mathrm{Ti}$, the surplus Ti continues to react with $\mathrm{Al}_{3} \mathrm{Ti}$ to form the Ti-Al compound, and then reacts with $\mathrm{C}$ to form $\mathrm{TiC}$ at about $1273 \mathrm{~K}$.

Obviously, the refining performance and phase distribution, morphologies, size of Al-T-C master alloys are seriously affected by the preparation process. Whereas, the mechanism of phases synthesis and refining are not uniform until now. Crossley and Mondolfo [26] proposed the peritectic theory according to the Al-Ti binary phase diagram. Wang et al [27] considered that the atom of Ti is provided by the dissolve of $\mathrm{Al}_{3} \mathrm{Ti}$, and then moves to $\mathrm{TiC}$, finally forming $\mathrm{Al}_{3} \mathrm{Ti}$ on the surface of $\mathrm{TiC}$. Subsequently, peritectic reaction occurred on the surface of Al3Ti to form $\alpha$-Al. Svynarenko et al [21] found that excess Ti can modify the growth and distribution of TiC.

This paper is supposed to investigate the process of the transformation of the phase and microstructure in the Al-5Ti-0.62C system by using the quenching experiment method. According to the thermodynamic calculation and DSC experiment, the synthesis mechanism of $\mathrm{TiC}$ in the Al-5Ti-0.62C system were researched. Particularly, this study provides a theoretical basis for the composition and process control of the Al-Ti-C master alloy. Besides, it also facilitates the preparation of high efficient and stable master alloy.

\section{Experimental Materials and Methods}

Al-5Ti-0.62C master alloy was prepared by the aluminum melt in-situ reaction, commercial pure aluminum (99.7 wt.\%, A99.7), pure Al powder (99.0 wt. $\%, 80-100 \mu \mathrm{m})$, pure Ti powder $(99.0$ wt. $\%, 45-65 \mu \mathrm{m})$, and graphite powder $(99.0 \mathrm{wt} . \%, 10-20 \mu \mathrm{m})$ were used as main raw materials (Tianjin Zhiyuan Chemical Reagent Co., Ltd, Tianjin, China). First, the powders were blended in the Pulaerisette-5 high-speed planetary ball mill (Nanjing Leibu Technology Industry Co., Ltd, Nanjing, China) at $350 \mathrm{r} / \mathrm{min}$ for $3 \mathrm{~h}$, and the ball to material ratio is 3:1. Then, the mixed powders were pressed into a cylindrical preform in a stainless steel mold $25 \mathrm{~mm}$ in diameter and $50 \mathrm{~mm}$ in height on an AG-10TA universal test stretching machine (Shimadzu Corporation, Kyoto, Japan), and the uniaxial pressure was set to $50 \mathrm{Mpa}$. Next, the preform was preheated to $473 \mathrm{~K}$ in a drying oven. Simultaneously, a certain amount of A99.7 ingots were melted in alumina crucible by using a SG-7.5-10 type crucible furnace (Zhonghuan experimental furnace corporation, Tianjin, China), the temperature was heated to $1053 \mathrm{~K}$. Subsequently, the preform was added into the A99.7 melt and held for $15 \mathrm{~min}$ to synthesize the Al-5Ti-0.62C master alloy, the flow chart is shown in Figure 1.

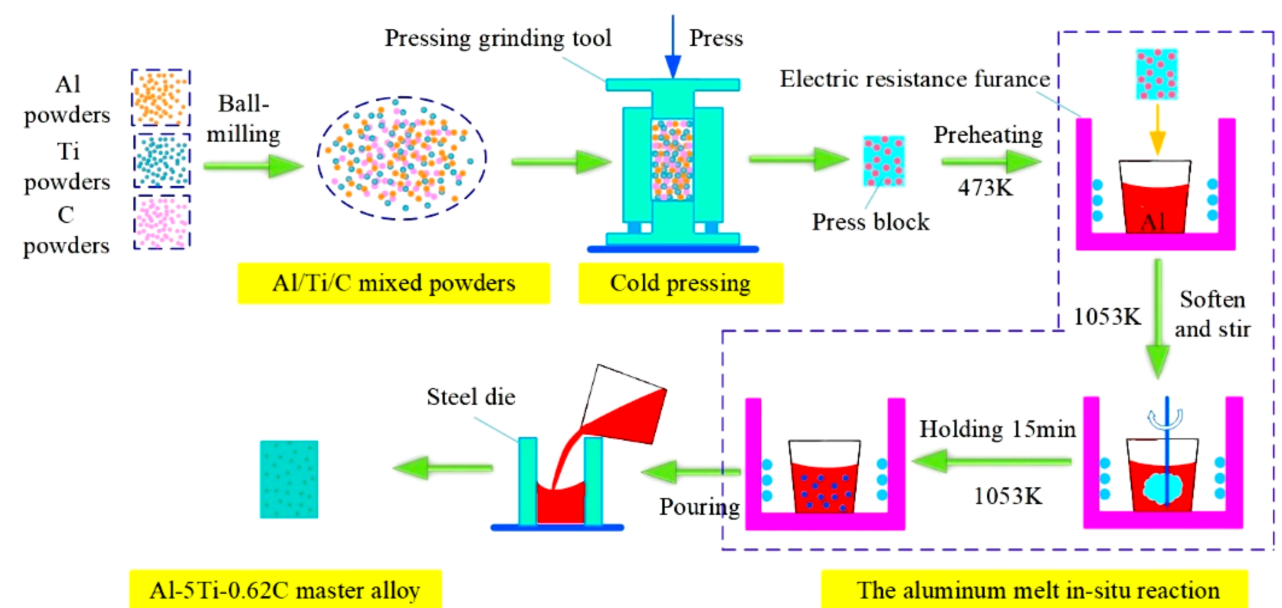

Figure 1. The experimental flow chart of the preparation of the Al-5Ti-0.62C master alloy. 
As shown in Figure 2, grain refining tests for the Al-5Ti-0.62C master alloy with different additions, i.e., $0 \%, 0.2 \%$, and $0.3 \%$, were carried out in order to evaluate its refining performance. After holding $5 \mathrm{~min}$, the melts were stirred thoroughly by a graphite rod. Then, it was poured into a dye. After solidification, the specimens with the height of $1 \mathrm{~cm}$ were cut from the ingots and etched by cross-section by a reagent $\left(45 \mathrm{~mL} \mathrm{HCl}+15 \mathrm{~mL} \mathrm{HNO}_{3}+15 \mathrm{~mL} \mathrm{HF}+25 \mathrm{~mL} \mathrm{H}_{2} \mathrm{O}\right)$ within about 15-20 s. At last, pictures of the macro-structure were taken for each sample by a camera.

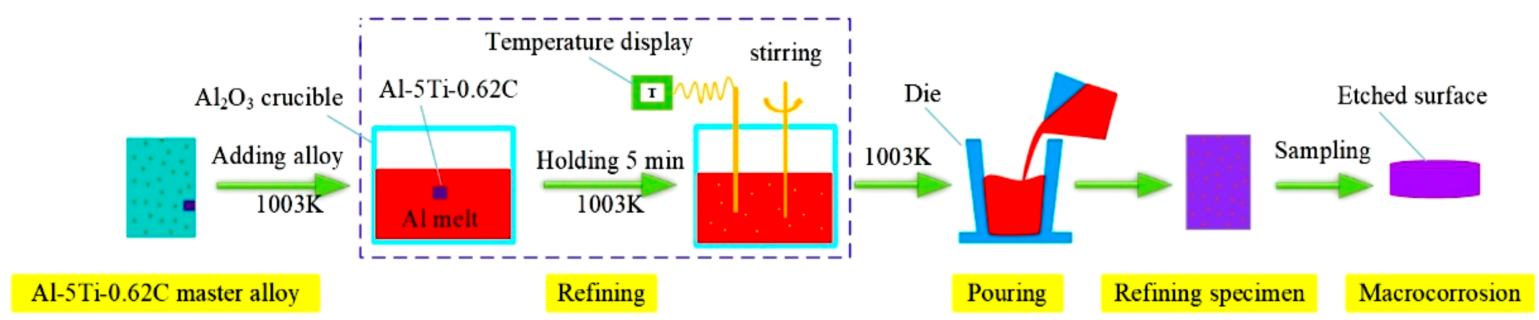

Figure 2. The experimental flow chart for refining commercial aluminum.

Furthermore, the typical quenching samples at different stages of the reaction were prepared in order to investigate the phase and microstructure transition of the Al-5Ti-0.62C master alloy. At first, the preform immersed in the A99.7 melt was quickly taken out after reacting to different times $(20,45$, $60,90,120 \mathrm{~s}$ ) with control by paperless recorder, and then was quenched in a high pressure ice brine stream. After cooling, the quenching samples were cut along the axis and then coarsely ground, finely ground, mechanically polished, and finally, electrolytic polished with a reagent $\left(10 \% \mathrm{HClO}_{4}+90 \%\right.$ absolute ethanol, the composition of here is volume fraction, voltage is $20 \mathrm{~V}$, at room temperature).

The phases in the quenched specimens and specimens for metallographic examinations were identified by D8 advance X-ray diffraction (XRD, Shimadzu Corporation, Kyoto, Japan, the tube has an accelerating voltage of $40 \mathrm{kV}$, an emission current of $40 \mathrm{~mA}, \mathrm{Cu} \mathrm{K} \alpha, \lambda=1.54156 \AA$, scanning speed of $10^{\circ} / \mathrm{min}$, step size of $0.02^{\circ}$, angle from 2 Theta $20^{\circ}$ to $90^{\circ}$ ). The morphology and composition of the quenching samples and metallographic specimen were characterized by JSM-6700F scanning electron microscope (SEM, Shimadzu Corporation, Kyoto, Japan), an energy dispersive spectrometer (EDS, Shimadzu Corporation, Kyoto, Japan), and an electron probe microanalyzer (EPMA, Shimadzu Corporation, Kyoto, Japan). Further, the DSC curve of the Al-5Ti-0.62C system was carried out on NETZSCH STA 449F3 instrument (NETZSCH, Hanau, Germany). Air flow protection was used, and the heating rate was selected as $20 \mathrm{~K} / \mathrm{min}$, also, the weight of the sample was less than $10 \mathrm{mg}$.

\section{Results and Discussion}

\subsection{The Microstructure of Al-5Ti-0.62C Master Alloy}

The XRD pattern and the SEM image of the Al-5Ti-0.62C master alloy are shown in Figure 3. It can be seen from Figure $3 \mathrm{a}$ that the main phases of the Al-5Ti-0.62 $\mathrm{C}$ master alloy are $\alpha-\mathrm{Al}_{1} \mathrm{Al}_{3} \mathrm{Ti}$, and $\mathrm{TiC}$. As shown in Figure $3 \mathrm{~b}$, the block-like particles with size of 5-8 $\mu \mathrm{m}$ are $\mathrm{Al}_{3} \mathrm{Ti}$, and the little near spherical particles with size of 1-3 $\mu \mathrm{m}$ are TiC. Besides, not only the $\mathrm{Al}_{3}$ Ti particles but also TiC particles are evenly distributed in the matrix, and $\mathrm{TiC}$ particles have not gathered together.

\subsection{Refining Effect Evaluation of Al-5Ti-0.62C Master Alloy}

The macrostructures of A99.7 with different Al-5Ti-0.62C master alloy additions are shown in Figure 4. As shown in Figure 4a, A99.7 without refiner is mainly composed of surrounding coarse central equiaxed crystals and columnar crystals. When adding $0.2 \%$ Al-5Ti-0.62C into A99.7, the macrostructure of A99.7 is almost completely transformed into fine equiaxed crystals, except for fine columnar crystals located in the edge, as shown in Figure $4 \mathrm{~b}$. It is clearly observed from Figure $4 \mathrm{c}$ 
that A99.7 is entirely refined into the fine equiaxed structure when the amount of Al-5Ti-0.62C added increases to $0.3 \%$.
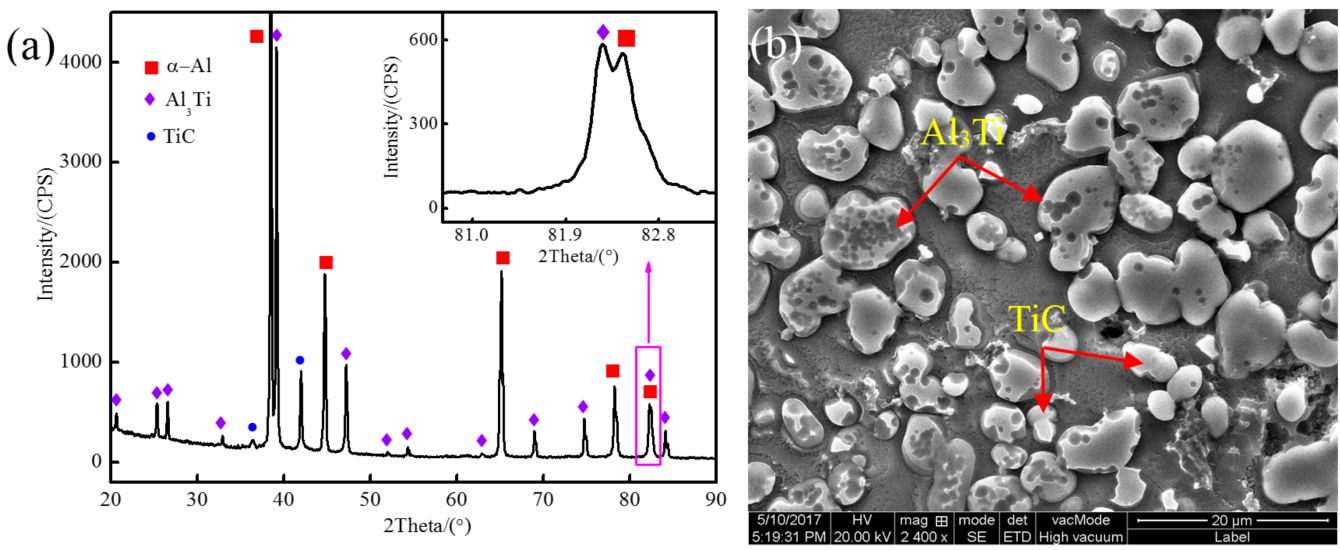

Figure 3. XRD pattern and SEM image of Al-5Ti-0.62C master alloy: (a) XRD pattern; (b) SEM image.
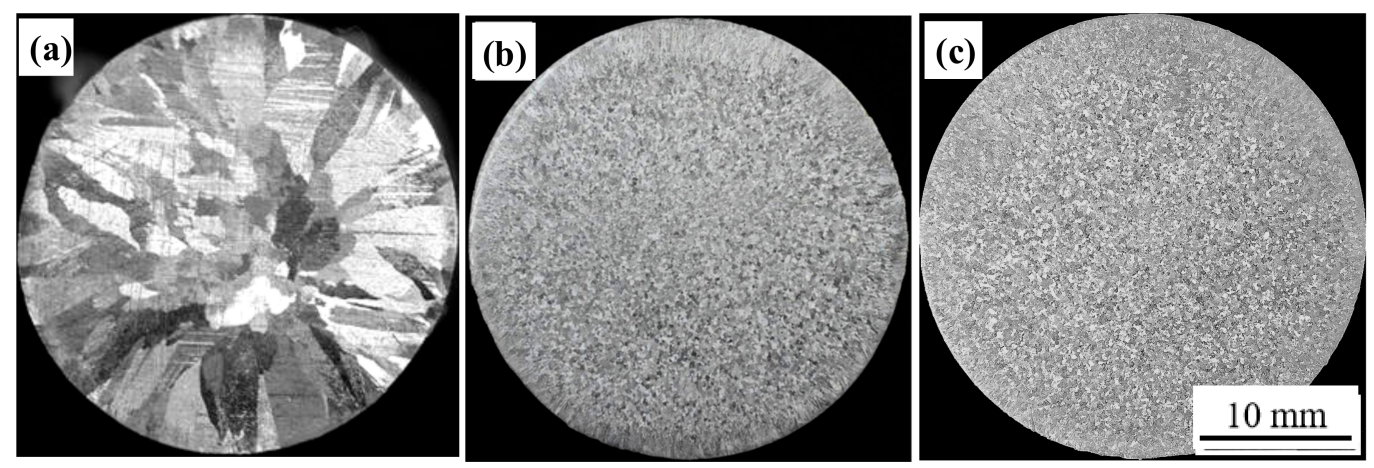

Figure 4. Macrostructures of A99.7 refined using the Al-5Ti-0.62C master alloy. (a) Without master alloy; (b) $0.2 \%$; (c) $0.3 \%$.

The results above indicate that the Al-5Ti-0.62C master alloys exhibit excellent refining effect on A99.7. The main reason is that TiC can be used as a heterogeneous nuclear of $\alpha-\mathrm{Al}[20,21,28]$. According to the literature reports $[29,30], \alpha-\mathrm{Al}$ and TiC all are face-centered cubic structure, lattice constant of TiC $\left(\mathrm{a}_{\mathrm{TiC}}\right)$ is $0.432 \mathrm{~nm}$, and lattice constant of $\alpha-\mathrm{Al}\left(\mathrm{a}_{\mathrm{Al}}\right)$ is $0.404 \mathrm{~nm}$, then the lattice mismatch $(\delta)$ between $\mathrm{Al}$ and $\mathrm{TiC}$ as Equation (1):

$$
\delta=\frac{\left(\mathrm{a}_{\mathrm{TiC}}\right)-\left(\mathrm{a}_{\mathrm{Al}}\right)}{\mathrm{a}_{\mathrm{Al}}} \times 100 \%
$$

From the point of crystallization, $\mathrm{TiC}$ is beneficial to promote the nucleation of $\alpha$-Al. Figure 5 shows the distribution of $\mathrm{TiC}$ in A99.7 after refining by the Al-5Ti-0.62C master alloy. The mapping analysis of the refining specimen with EPMA is shown in Figure 6. Figure 5a,b demonstrates that the $\mathrm{TiC}$ particles are mainly distributed in the core of the grain and aggregated on the grain boundary. From crystallographic considerations, in virtue of $\mathrm{TiC}$ and $\mathrm{Al}$ have a good orientation relationship, and the lattice mismatch between $\mathrm{Al}$ and $\mathrm{TiC}$ is $6.9 \%$, which is less than $25 \%$ and larger than $5 \%$. Namely, there is a semi-coherent interface between the TiC substrate and $\alpha$ - $\mathrm{Al}$ matrix, which can promote the heterogeneous nucleation ability of the $\alpha$-Al matrix. Combined with the mapping analysis results, which are exhibited in Figure 6, the Ti elements mainly distribute around the TiC particles with a concentration gradient. Hence, $\mathrm{Al}_{3} \mathrm{Ti}$ will rapidly dissolve into $\mathrm{Ti}$ atoms and liquid $\mathrm{Al}$ when the Al-5Ti-0.62C master alloy was added into the Al melt, and then the dissolved Ti atoms will spread around the $\mathrm{TiC}$ particles to form the Ti concentration gradient, and finally form $\mathrm{Al}$ dendrite on the surface of the TiC particles by the Ti-rich zone, which demonstrate that $\mathrm{TiC}$ particles promote the $\alpha-\mathrm{Al}$ 
nucleation. Furthermore, the amount of TiC particles is distributed at the grain boundary to limit the growth of the Al grains.

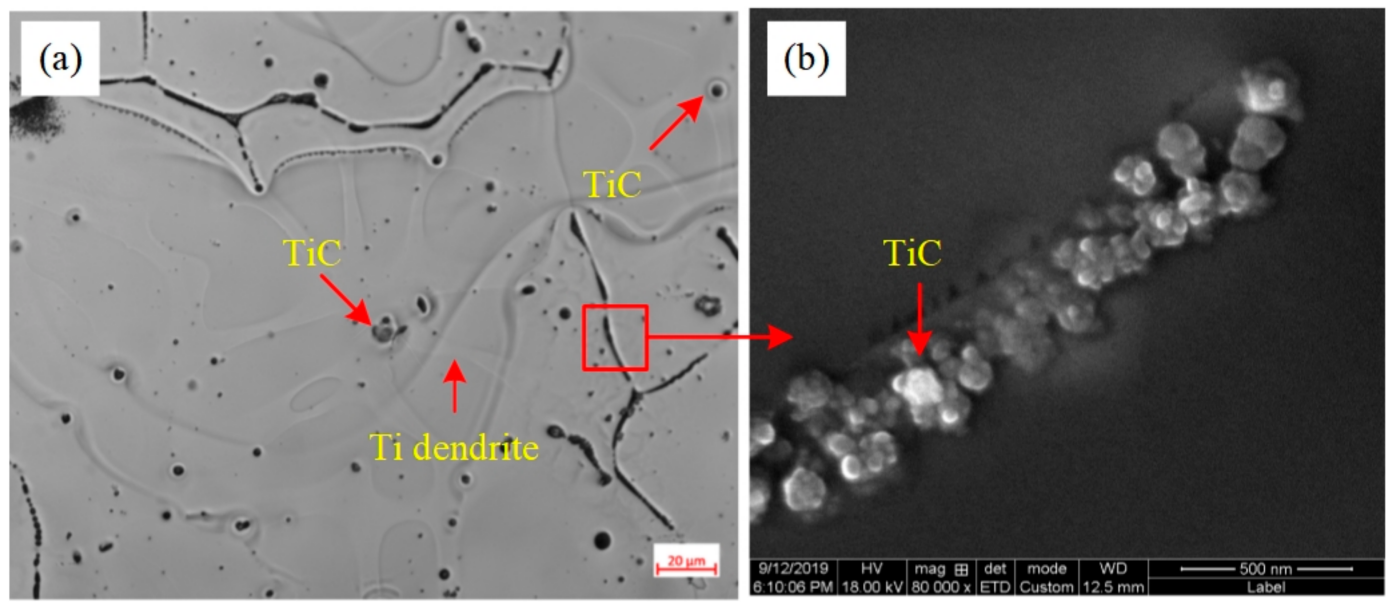

Figure 5. The grain morphologies of the distribution of $\mathrm{TiC}$ in A99.7 after refining: (a) OM image of A99.7; (b) SEM image on the grain boundary.
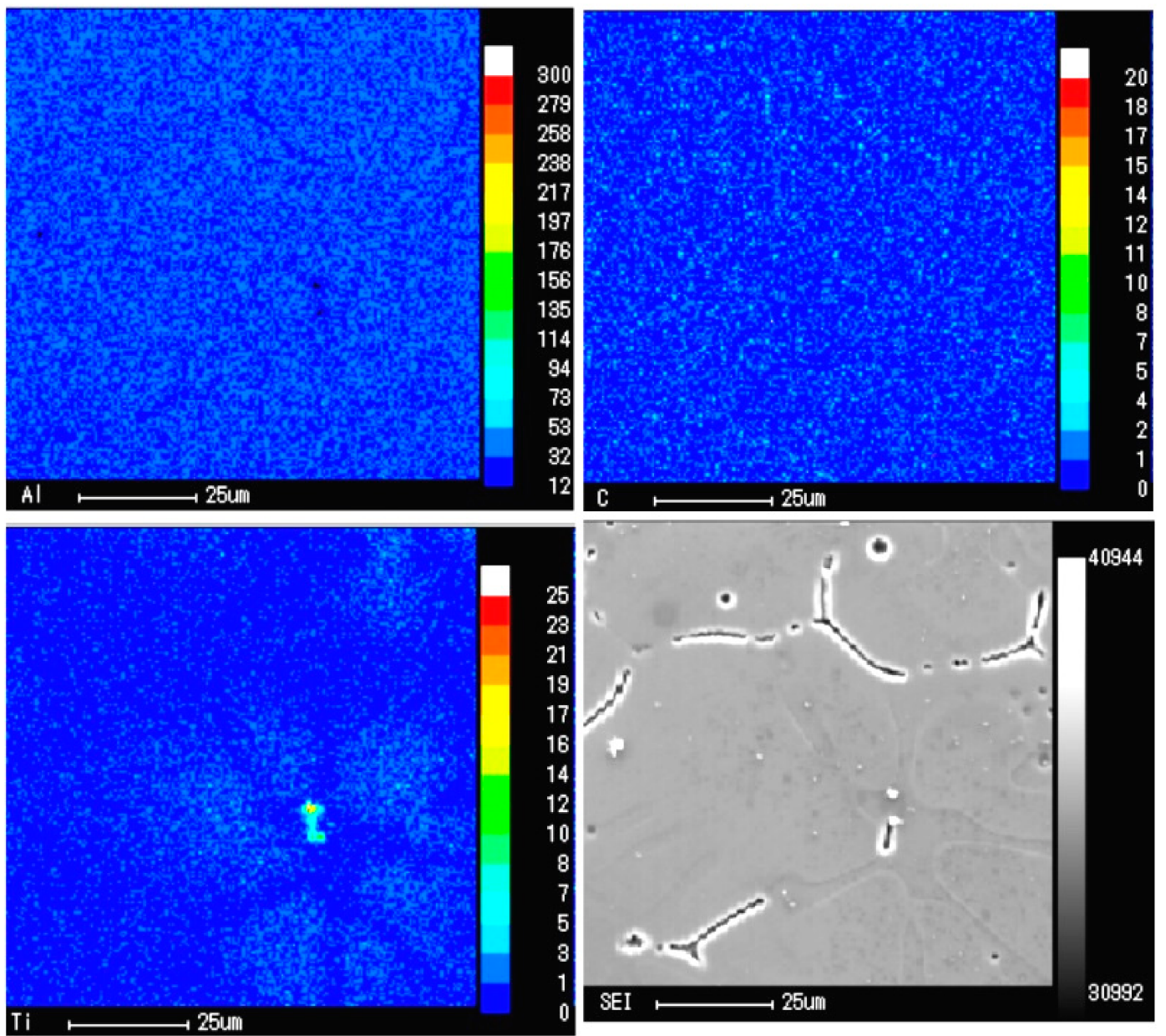

Figure 6. EPMA mapping analysis of A99.7 with the Al-5Ti-0.62C master alloy.

The schematic diagram of the nucleation and growth process of $\alpha$-Al after adding Al-5Ti-0.62C into the melt is shown in Figure 7. In the process of solidification, TiC particles are free in the melt at first, then the excess $\mathrm{Ti}$ atoms segregate around $\mathrm{TiC}$ to form a concentration gradient. Subsequently, 
some $\mathrm{TiC}$ particles are located in the grain, then Ti atoms, which generally form into a Ti-rich zone around $\mathrm{TiC}$, promote the nucleation of dendrite $\alpha$-Al. After solidification, Ti elements with the lace structure are wrapped inside the grain [27]. Some research explained that when the concentration of $\mathrm{Ti}$ reaches a certain level, a thin layer of $\mathrm{Al}_{3} \mathrm{Ti}$ will be formed on the TiC surface, and $\mathrm{Al}_{3} \mathrm{Ti}$ will react with the surrounding aluminum solution to form $\alpha$-Al during the solidification process. In the subsequent cooling process, the first Ti-rich $\alpha-\mathrm{Al}$ formed by the peritectic reaction was surrounded by the later Ti-poor $\alpha$-Al formed. The central Ti was not easy to diffuse outward, so the composition gradient of Ti was formed in the $\alpha-\mathrm{Al}$, and the contrast was formed after erosion [31,32].

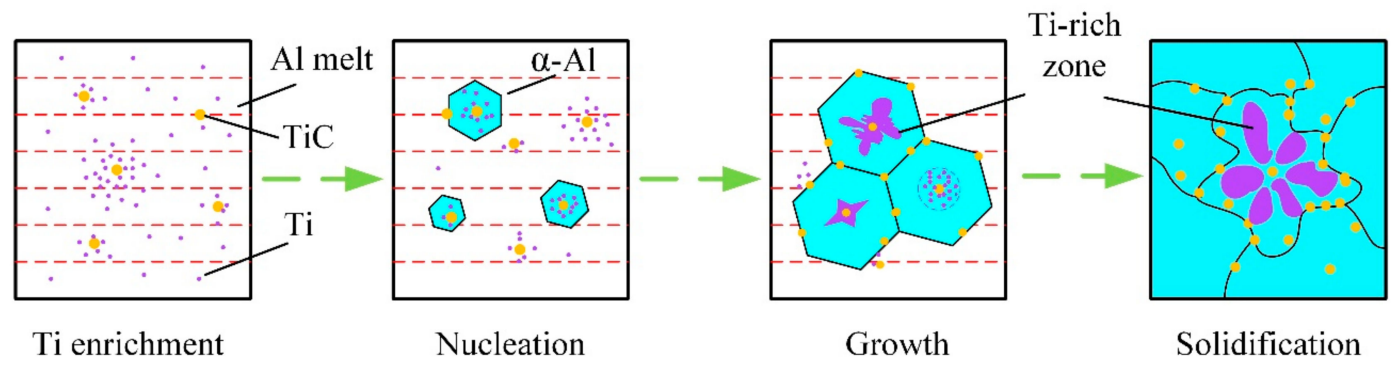

Figure 7. The schematic diagram of the nucleation and growth process of $\alpha$-Al.

\subsection{Phase Transformation and Microstructure Transformation of Al-Ti-C System}

After adding the preform block into the A99.7 melt, the temperature of the preform block will increase rapidly, and liquid $\mathrm{Al}$ in the melt will infiltrate into the preform block. Then, the solid Ti will react with liquid $\mathrm{Al}$ to form $\mathrm{Al}_{3} \mathrm{Ti}$. Also, solid $\mathrm{Al}$ particles melt into liquid $\mathrm{Al}$ [33]:

$$
\begin{array}{ll}
3 \mathrm{Al}(\mathrm{l})+\mathrm{Ti}(\mathrm{s})=\mathrm{Al}_{3} \operatorname{Ti}(\mathrm{s}) & \Delta \mathrm{G}_{1}, \\
\mathrm{Al}(\mathrm{s})=\mathrm{Al}(\mathrm{l}) & \Delta \mathrm{G}_{2} .
\end{array}
$$

Subsequently, solid Ti particles are dissolved into $\mathrm{Ti}$ atoms and diffused into the $\mathrm{Al}$ melt. Afterwards, Ti atoms gather around solid $\mathrm{C}$ particles and react with $\mathrm{C}$ to form TiC. An amount of literature reports that $\mathrm{TiC}$ is mainly formed by the reaction between excess $\mathrm{Ti}$ or formed $\mathrm{Al}_{3} \mathrm{Ti}$ and solid C [20,34]:

$$
\begin{array}{lc}
\operatorname{Ti}(\mathrm{s})=[\mathrm{Ti}] & \Delta \mathrm{G}_{3}, \\
\mathrm{Al}_{3} \mathrm{Ti}(\mathrm{s})+\mathrm{C}(\mathrm{s})=\mathrm{TiC}(\mathrm{s})+3 \mathrm{Al}(\mathrm{l}) & \Delta \mathrm{G}_{4}, \\
{[\mathrm{Ti}]+\mathrm{C}(\mathrm{s})=\mathrm{TiC}(\mathrm{s})} & \Delta \mathrm{G}_{5} .
\end{array}
$$

Furthermore, solid $\mathrm{C}$ in the $\mathrm{Al}$ melt also can be dissolved into $\mathrm{C}$ atoms and combined with $\mathrm{Ti}$ atoms to form TiC. Besides, solid $\mathrm{C}$ can react with $\mathrm{Al}$ to form $\mathrm{Al}_{4} \mathrm{C}_{3}$, and then $\mathrm{Al}_{4} \mathrm{C}_{3}$ will react with the Ti atom to form TiC [19,35], the reaction equations as follows:

$$
\begin{array}{ll}
\mathrm{C}(\mathrm{s})=[\mathrm{C}] & \Delta \mathrm{G}_{6}, \\
{[\mathrm{Ti}]+[\mathrm{C}]=\mathrm{TiC}(\mathrm{s})} & \Delta \mathrm{G}_{7}, \\
4 \mathrm{Al}(\mathrm{l})+3 \mathrm{C}(\mathrm{s})=\mathrm{Al}_{4} \mathrm{C}_{3}(\mathrm{~s}) & \Delta \mathrm{G}_{8}, \\
1 / 3 \mathrm{Al}_{4} \mathrm{C}_{3}(\mathrm{~s})+[\mathrm{Ti}]=\mathrm{TiC}(\mathrm{s})+4 / 3 \mathrm{Al}(\mathrm{l}) & \Delta \mathrm{G}_{9}, \\
\mathrm{Al}_{3} \mathrm{Ti}(\mathrm{s})=3 \mathrm{Al}(\mathrm{l})+[\mathrm{Ti}] &
\end{array}
$$

where [Ti] and $[\mathrm{C}]$ present the dissolved Ti and $\mathrm{C}$ in the melt. The Gibbs free energy changes curves above formulas are shown in Figure 8. It can be seen that $\Delta G_{1}<0$, and $\Delta G_{2}<0$ when the temperature is larger than $\mathrm{T} 1$ (that is the melt point of $\mathrm{Al}, 933 \mathrm{~K}$ ). In addition, $\Delta \mathrm{G}_{3}$ to $\Delta \mathrm{G}_{5}$ and $\Delta \mathrm{G}_{3}$ to $\Delta \mathrm{G}_{9}$ are 
also less than zero. In view of thermodynamics, Equations (2), (4)-(6) and (8)-(10) can be carried out spontaneously, and solid Al will spontaneously transfer into liquid Al when $\mathrm{T} \geq 933 \mathrm{~K}$. For Equation (7), $\Delta \mathrm{G}_{6}>0$ until the temperature is equal to $\mathrm{T} 4(1550 \mathrm{~K})$, that is, Equation (7) can be carried out spontaneously only when the temperature is greater than T4. In addition, Equation (2) will release a lot of heat, which will increase the local temperature rapidly. Y.F. Hou [36] researched that when the in-situ reaction of the aluminum melt occurs to prepare Al-Ti-C by quenching experiment, the local temperature will reach about $1600 \mathrm{~K}$, which is consistent with the theoretical thermodynamic data in previous research. In other words, Equation (2) can promote the occurrence of Equations (7) and (8). However, the solubility of $\mathrm{C}$ in liquid $\mathrm{Al}$ is very low. The study of Dorward [37] shows that the dissolution of $\mathrm{C}$ in $\mathrm{Al}$ melt is about $10^{-5} \mathrm{wt} . \%$ at $973 \mathrm{~K}$, and only about $3 \times 10^{-4}$ wt.\% at $1273 \mathrm{~K}$. Therefore, from the thermodynamic point of view, the tendency of forming $\mathrm{TiC}$ in Equation (8) is lower than Equation (6). The possible compounds in the $\mathrm{Al}-\mathrm{Ti}-\mathrm{C}$ system are $\mathrm{Al}_{3} \mathrm{Ti}, \mathrm{Al}_{4} \mathrm{C}_{3}$, and $\mathrm{TiC}$, compared with $\Delta G_{1}, \Delta G_{5}, \Delta G_{8}$, and $\Delta G_{9}$, the value of the Gibbs free energy of Equation (10) is the most negative, so, $\mathrm{TiC}$ is the most stable phase, $\mathrm{Al}_{3} \mathrm{Ti}$ and $\mathrm{Al}_{4} \mathrm{C}_{3}$ will dissolve or react with other substances when $\mathrm{T}<\mathrm{T} 3$ as in Equation (11). The stability of the phase is $\mathrm{TiC}>\mathrm{Al}_{3} \mathrm{Ti}>\mathrm{Al}_{4} \mathrm{C}_{3}$ in turn when $\mathrm{T}<\mathrm{T} 2$, Banerji and Reif [38] believe that at $1273 \mathrm{~K}, \mathrm{C}$ will not wet and react with $\mathrm{Al}$, also, as shown in Figure 3, $\mathrm{Al}_{4} \mathrm{C}_{3}$ is not formed in Al-5Ti-0.62C master alloy, hence Equations (9) and (10) will not occur at the experiment temperature. As previously mentioned, $\mathrm{TiC}$ is likely formed by $\mathrm{Ti}$ atoms and solid $\mathrm{C}$.

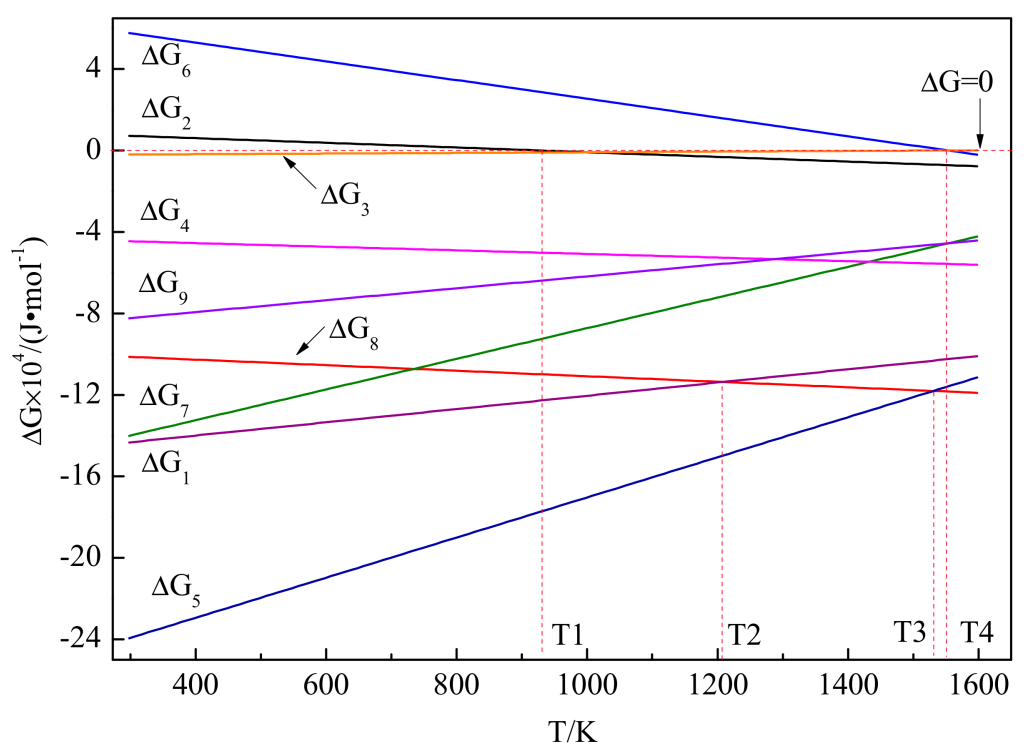

Figure 8. The Gibbs free energy changes curves of the reaction in the Al-5Ti-0.62C system.

The reaction processes among $\mathrm{Al}, \mathrm{Ti}$, and $\mathrm{C}$ powders mixtures of the Al-5Ti-0.62C system identified by the DSC curve is shown in Figure 9. One endothermic peak and two exothermic peaks are shown in Figure 9. According to the above thermodynamic analysis and related literatures [39,40], and combined with the analysis of the Al-Ti binary phase diagram [33] and A-Ti-C ternary phase diagram [41,42], the first endothermic peak characterizes the melted of $\mathrm{Al}$ which corresponds to Equation (3) at 943.9 K. The first exothermic peak at $1193.9 \mathrm{~K}$ is presented by the formation of $\mathrm{Al}_{3} \mathrm{Ti}$ and is illustrated in Equation (2), the second exothermic peak at $1399.7 \mathrm{~K}$ is presented by the formation of $\mathrm{TiC}$ and is shown in Equation (6).

In order to study the phase transformation and microstructure transformation in the synthetic process of Al-5Ti-0.62C, the Al-5Ti-0.62C preform block was prepared and the microstructure under different reaction times in the melt was investigated. The XRD patterns of the quenched samples at different times are shown in Figure 10. It can be seen from Figure 10a,b that the main phases of the preform are $\alpha-\mathrm{Al}, \mathrm{Ti}$, and $\mathrm{C}$ at the initial stage $\left(20 \mathrm{~s}\right.$ and $45 \mathrm{~s}$ ). When the reaction time is $60 \mathrm{~s}, \mathrm{Al}_{3} \mathrm{Ti}$ 
and TiC phases were detected by XRD as shown in Figure 10c. Furthermore, when the reaction time increases, the diffraction peaks intensity of $\mathrm{Al}_{3} \mathrm{Ti}$ and $\mathrm{TiC}$ phases gradually increase, as shown in Figure 10c-e.

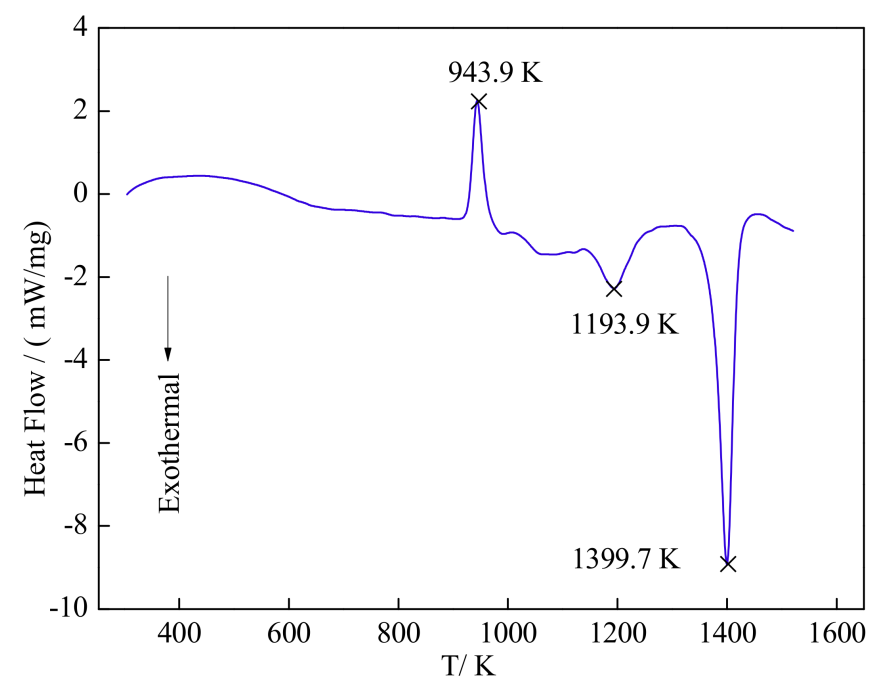

Figure 9. DSC curves of the Al-5Ti-0.62C system.

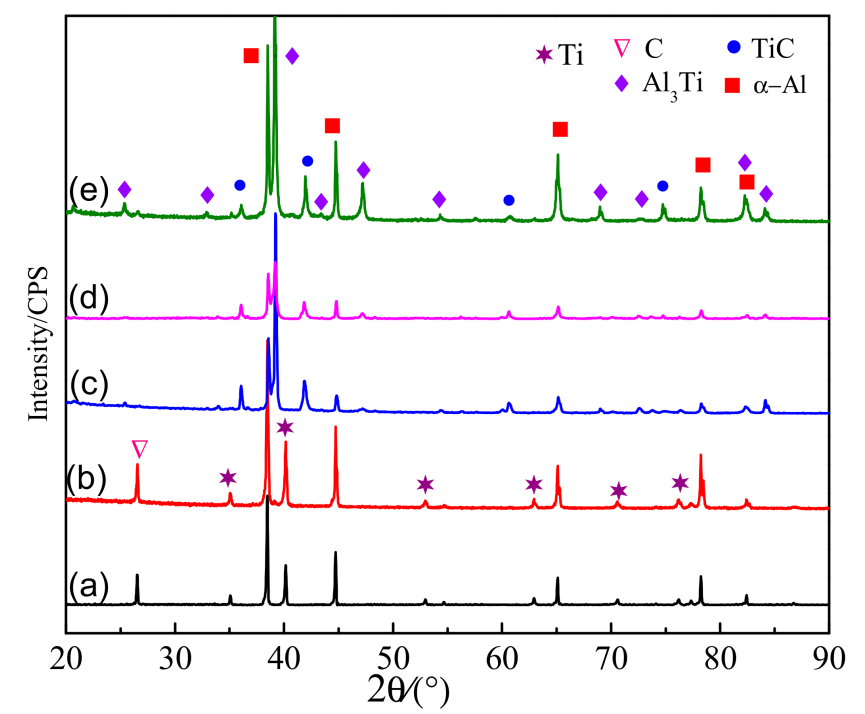

Figure 10. XRD patterns of the quenched samples with different reaction times: (a) $20 \mathrm{~s}$; (b) $45 \mathrm{~s}$; (c) 60 s; (d) $90 \mathrm{~s}$; (e) $120 \mathrm{~s}$.

The SEM images and map scan patterns of the quenched sample at $120 \mathrm{~s}$ are shown in Figure 11. Table 1 shows EDS composition analysis of point $A$, point $B$, and point $C$ in Figure 11. Figure 12 shows the line scan patterns of line 1 of Figure 11a. As can be seen from Figure 11, when the reaction time reaches $120 \mathrm{~s}$, an amount of lace structure is presented in the melt as shown in Figure 11a. Combined with the results of the map scan patterns of Figure 11c-e, the center of the lace structure is the Ti particle, and $\mathrm{Al}$, Ti elements are enriched at the edge of the lace structure. Further, Ti and $\mathrm{C}$ elements are surrounded by the lace structure. Moreover, the results of the EDS shows that Al:Ti of point A closely equals to 3:1, Ti:C of point $\mathrm{B}$ and $\mathrm{C}$ approximately equal to 1:1. A conclusion can be drawn that the block-like particles with the size of $\sim 6 \mu \mathrm{m}$ are $\mathrm{Al}_{3} \mathrm{Ti}$ at the edge of lace structure, and the particles with the size of $\sim 1 \mu \mathrm{m}$ are $\mathrm{TiC}$ around the lace structure. It can be seen from Figure 12 that the contents of the Ti elements from A to E show a decreasing tendency, and C elements mainly enrich in the $\mathrm{AB}$ 
stage and DE stage, the $C$ element in the AB stage also has a tendency to spread outward, and in the DE stage, exiting in forms of TiC which is certified by EDS of point $\mathrm{B}$ and point $\mathrm{C}$.
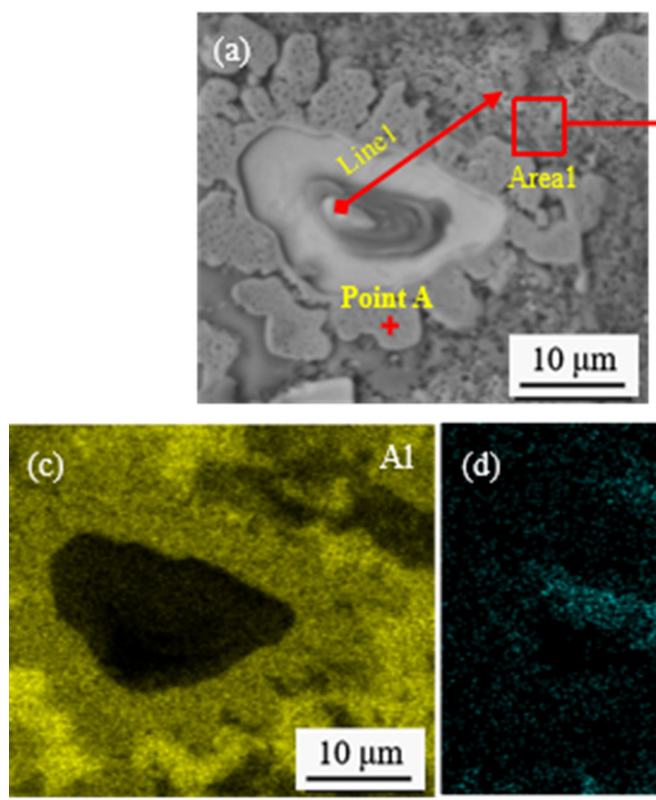
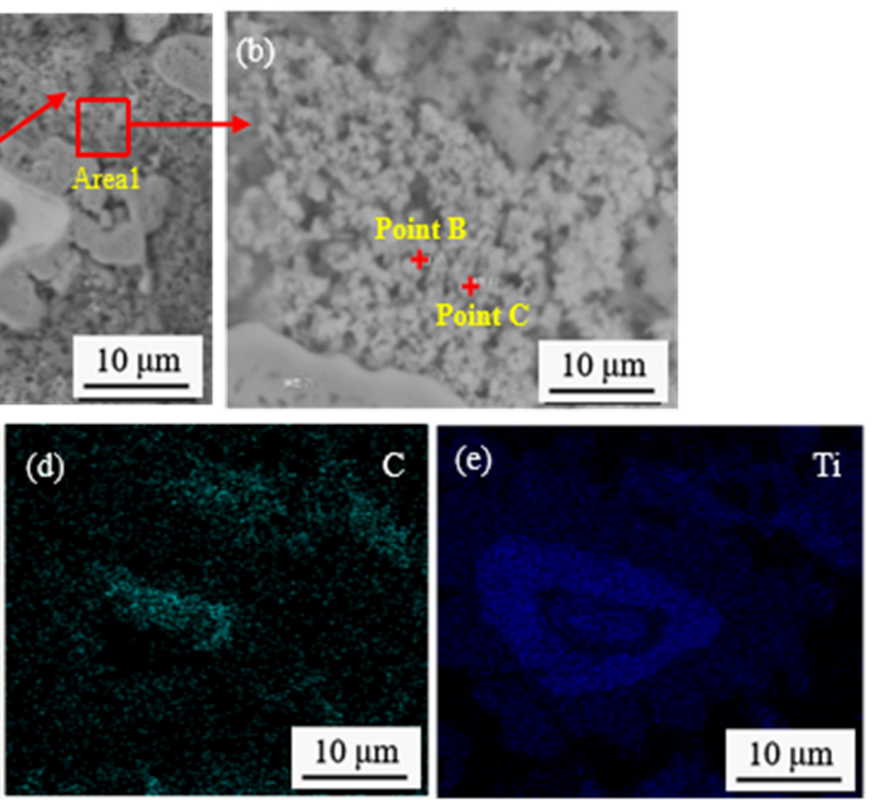

Figure 11. SEM images and map scan patterns of the quenched sample at 120 s: (a) SEM image; (b) SEM image of Area 1; (c-e) map scan patterns of $\mathrm{Al}, \mathrm{C}$, and $\mathrm{Ti}$, respectively.

Table 1. The energy dispersive spectrometer (EDS) composition analysis of point A, point B, and point $\mathrm{C}$ in Figure $11 \mathrm{~b}$.

\begin{tabular}{cccc}
\hline Point No. & Atomic (Al)/\% & Atomic (Ti)/\% & Atomic (C)/\% \\
\hline A & 70.6 & 25.7 & 3.6 \\
B & 13.2 & 41.7 & 45.2 \\
C & 10.4 & 40.5 & 49.1 \\
\hline
\end{tabular}
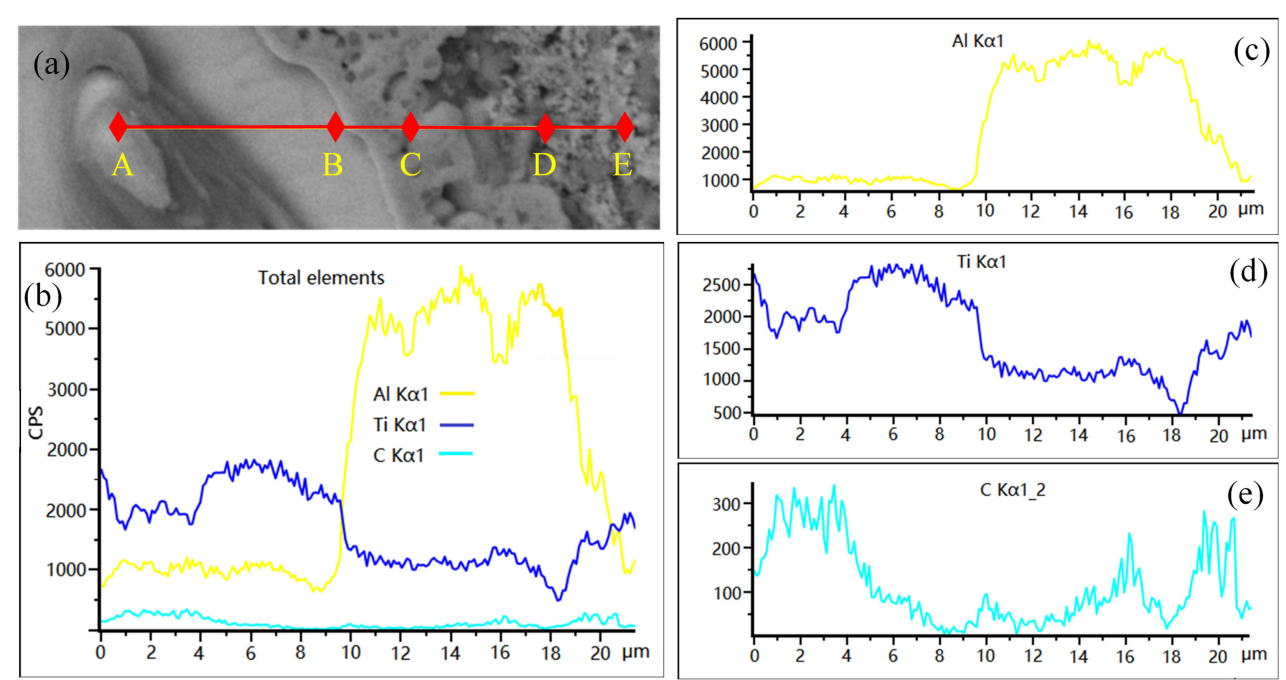

Figure 12. SEM image and line scan patterns of Line 1 of Figure 11a: (a) SEM image; (b) line scan patterns of all elements; (c-e) line scan patterns of $\mathrm{Al}, \mathrm{Ti}$, and $\mathrm{C}$, respectively.

The lace structure model of the Al-5Ti-0.62C system is shown in Figure 13. An amount of research reports that the wettability of $\mathrm{Al}$ and $\mathrm{Ti}$ is much higher than that of $\mathrm{Al}$ and $\mathrm{C}$, therefore, liquid $\mathrm{Al}$ will rapidly spread on the surface of Ti particles after Al particles have melted, because the solubility of 
titanium in aluminum is very small, so it is rapidly saturated at the interface of the Al-Ti layer. Then, with the reaction of $\mathrm{Al}$ and $\mathrm{Ti}$, the $\mathrm{Al}_{3} \mathrm{Ti}$ nucleus grows up to form $\mathrm{Al}_{3} \mathrm{Ti}$ particles. Moreover, because of the brittleness of $\mathrm{Al}_{3} \mathrm{Ti}$, it is separated from the $\mathrm{Al}-\mathrm{Ti}$ interface and entered into the $\mathrm{Al}$ solution under the continuous impact of liquid aluminum. Next, liquid aluminum flows into the gap of $\mathrm{Al}_{3} \mathrm{Ti}$ after separation, and continues to react with $\mathrm{Ti}$ to form $\mathrm{Al}_{3} \mathrm{Ti}$, subsequently, $\mathrm{Al}_{3} \mathrm{Ti}$ breaks away from the $\mathrm{Al}-\mathrm{Ti}$ interface and enters into the $\mathrm{Al}$ solution, and promotes the front $\mathrm{Al}_{3} \mathrm{Ti}$ particles to float away from the interface. In addition, the formation of $\mathrm{Al}_{3} \mathrm{Ti}$ will release a lot of heat, which will increase the local temperature to about $1600 \mathrm{~K}$. Nevertheless, the melting point of $\mathrm{Al}_{3} \mathrm{Ti}$ is $1613 \mathrm{~K}$, hence that it will cause the $\mathrm{Al}_{3} \mathrm{Ti}$ to fuse and break away from the $\mathrm{Al}$-Ti layer. So, over and over again, until enough $\mathrm{Al}_{3} \mathrm{Ti}$ particles are distributed near the interface, the flow of liquid aluminum is blocked and the impact force is not enough to separate the $\mathrm{Al}_{3} \mathrm{Ti}$ particles from the titanium base wall. Subsequently, $\mathrm{Al}_{3} \mathrm{Ti}$ or $\mathrm{Ti}$ atoms provided by the $\mathrm{Al}_{3} \mathrm{Ti}$ diffusion reaction with the solid $\mathrm{C}$ form TiC particles.

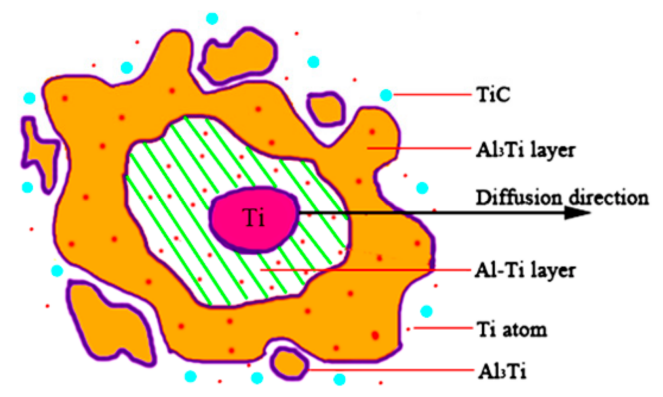

Figure 13. The lace structure model of the Al-5Ti-0.62C system.

The micro-kinetic model of TiC synthesis of the Al-5Ti-0.62C system is established by the analysis of the thermodynamic analysis of the Al-5Ti-0.62C system as shown in Figure 14. The TiC synthesis can be divided into three micro domains in the micro-region: the first micro-region is the generation of $\mathrm{Al}_{3} \mathrm{Ti}$ particles. When the preform block is put into the aluminum melt, the liquid aluminum in the aluminum melt penetrates into the preform block, so that the internal temperature of the prefabricated block is increased, afterwards, the aluminum powder is melted, and then the aluminum powder is wrapped on the surface of the Ti particles, hence, the Al-Ti layer is formed around the Ti particles by virtue of the solid-liquid diffusion, so the reaction I takes place. The second micro region is the dissolution of $\mathrm{Al}_{3} \mathrm{Ti}$ particles. As the reaction $\mathrm{I}$ is an exothermic reaction, the $\mathrm{Al}_{3} \mathrm{Ti}$ particles are separated from the $\mathrm{Al}-\mathrm{Ti}$ layer as the reaction proceeds, and the $\mathrm{Al}_{3} \mathrm{Ti}$ particles undergo a dissolution reaction II under the action of high temperature, and the generated $\mathrm{Ti}$ is migrated to the third micro-region, and the generation of the $\mathrm{TiC}$ particles is provided [Ti]. The third micro-region is mainly the formation of $\mathrm{TiC}$ particles. The [Ti] of the second micro-region forms a titanium-rich layer around the C-particles, and the solid-state carbon reacts with $\mathrm{Ti}$ atoms provided the dissolved $\mathrm{Al}_{3} \mathrm{Ti}$ generates $\mathrm{TiC}$ particles. As the reaction proceeds, $\mathrm{TiC}$ is separated from the titanium-rich layer and free in the melt.

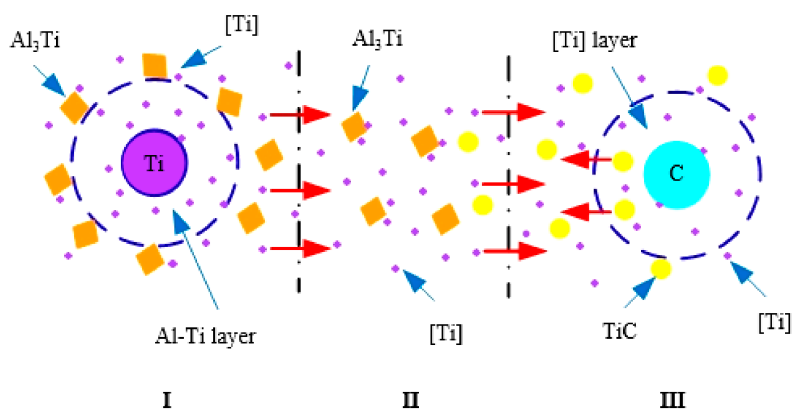

Figure 14. Microscopic kinetic model of TiC synthesis in the Al-5Ti-0.62C system. (I) $3 \mathrm{Al}(\mathrm{l})+\mathrm{Ti}(\mathrm{s}) \rightarrow$ $\mathrm{Al}_{3} \mathrm{Ti}(\mathrm{s}),(\mathrm{II}) \mathrm{Al}_{3} \mathrm{Ti}(\mathrm{s}) \rightarrow[\mathrm{Ti}]+3 \mathrm{Al}(\mathrm{l}),(\mathrm{III})[\mathrm{Ti}]+\mathrm{C}(\mathrm{s}) \rightarrow \mathrm{TiC}(\mathrm{s})$. 


\section{Conclusions}

(1) Al-5Ti-0.62C master alloys have a good refining effect on A99.7. A99.7 is completely refined into the fine equiaxed structure by adding $0.3 \%$ Al-5Ti-0.62C master alloy.

(2) When the Al-5Ti-0.62C master alloy is added into the melt, TiC particles mainly distribute in the grain interior and aggregate on the grain boundaries, excess Ti provided by the dissolved $\mathrm{Al}_{3} \mathrm{Ti}$ will spread around $\mathrm{TiC}$ and finally form a Ti-rich zone to promote the nucleation of $\alpha-\mathrm{Al}$.

(3) From the view of thermodynamics and dynamics, TiC is formed by the reaction between solid $\mathrm{C}$ and $\mathrm{Ti}$ atom provided by the dissolved $\mathrm{Al}_{3} \mathrm{Ti}$.

(4) The main reactions in the Al-5Ti-0.62C system are confirmed by DSC, that is, solid Al is transferred into liquid $\mathrm{Al}$, and then liquid $\mathrm{Al}$ reacts with solid $\mathrm{Ti}$ to form the $\mathrm{Al}_{3} \mathrm{Ti}$, and release a lots of heat to promote the formation of $\mathrm{TiC}$ which is formed by the $\mathrm{Ti}$ atoms and solid $\mathrm{C}$.

Author Contributions: W.D. and T.C. conceived and designed the experiments; W.D., T.C., X.Z., X.L. and L.G. carried out the experiments and data collection; W.D., Y.C. and T.C. analyzed the data; W.D. contributed reagents/materials/analysis tools; T.C. wrote the paper. All authors have read and agreed to the published version of the manuscript.

Funding: This work was supported by the National Natural Science Foundation of China "grant number 51661021 and 51665033" and the National Natural Science Foundation of Gansu, "grant number1606RJZA16 and 1308RJZA291". The authors would like to acknowledge the financial support of Gansu key research and development program by18YF1GA061 and China Postdoctoral Science Foundation by 2019M653896XB.

Conflicts of Interest: The authors declare no conflict of interest.

\section{References}

1. Lin, Y.C.; Luo, S.C.; Huang, J.; Yin, L.X.; Jiang, X.Y. Effects of solution treatment on microstructures and micro-hardness of a Sr-modified Al-Si-Mg alloy. Mater. Sci. Eng. A 2018, 725, 530-540. [CrossRef]

2. Karakoc, H.; Karabulut, S.; Citak, R. Study on mechanical and ballistic performances of boron carbide reinforced Al 6061 aluminum alloy produced by powder metallurgy. Compos. Part B 2018, 148, 68-80. [CrossRef]

3. Li, Q.L.; Li, B.Q.; Li, J.B.; Zhu, Y.Q.; Xia, T.D. Effect of yttrium addition on the microstructures and mechanical properties of hypereutectic Al-20Si alloy. Mater. Sci. Eng. A 2018, 732, 47-57. [CrossRef]

4. Liu, G.L.; Si, N.C.; Sun, S.C.; Wu, Q.F. Effects of grain refining and modification on mechanical properties and microstructure of Al-7Si-4Cu cast alloy. Trans. Nonferrous Met. Soc. China 2014, 24, 946-953. [CrossRef]

5. Li, P.T.; Liu, S.D.; Zhang, L.L.; Liu, X.F. Grain refinement of A356 alloy by Al-Ti-B-C master alloy and its effect on mechanical properties. Mater. Des. 2013, 47, 522-528. [CrossRef]

6. Yang, H.B.; Gao, T.; Zhang, H.N.; Nie, J.F.; Liu, X.F. Enhanced age-hardening behavior in Al-Cu alloys induced by in-situ synthesized TiC nanoparticles. J. Mater. Sci. Technol. 2019, 35, 374-382. [CrossRef]

7. Nie, J.F.; Wang, F.; Li, Y.S.; Liu, Y.F.; Liu, X.F.; Zhao, Y.H. Microstructure and mechanical properties of Al-TiB2/TiC in situ composites improved via hot rolling. Trans. Nonferrous Met. Soc. China 2017, 27, 2548-2554. [CrossRef]

8. Pramod, S.L.; Rao, A.K.P.; Murty, B.S.; Srinivasa, R.B. Microstructure and mechanical properties of as-cast and T6 treated Sc modified A356-5TiB 2 in-situ composite. Mater. Sci. Eng. A 2019, 739, 383-394. [CrossRef]

9. Cibula, A. The mechanism of grain refinement of sand casting in aluminum alloy. J. Inst. Met. 1949, 76, 321-360.

10. Kori, S.A.; Auradi, V. Influence of reaction temperature for the manufacturing of Al-3Ti and Al-3B master alloys and their grain refining efficiency on a Al-7Si alloy. Adv. Mater. Res. 2007, 29, 111-115. [CrossRef]

11. Sun, J.Y.; Li, C.; Liu, X.F.; Li, H.J.; Liu, Y.C. Investigation on AlP as the heterogeneous nucleus of $\mathrm{Mg}_{2} \mathrm{Si}$ in $\mathrm{Al}-\mathrm{Mg}_{2} \mathrm{Si}$ alloys by experimental observation and first-principles calculation. Results Phys. 2018, 8, 146-152. [CrossRef]

12. Kumar, G.S.V.; Murty, B.S.; Chakraborty, M. Grain refinement response of LM25 alloy towards Al-Ti-C and Al-Ti-B grain refiners. J. Alloys Compd. 2009, 472, 112-120. [CrossRef]

13. Wang, Y.; Fang, C.M.; Zhou, L.; Hashimoto, T.; Zhou, X.; Ramasse, Q.M.; Fan, Z. Mechanism for Zr poisoning of Al-Ti-B based grain refiner. Acta Mater. 2019, 164, 428-439. [CrossRef] 
14. Jiang, H.X.; Sun, Q.; Zhang, L.L.; Zhao, J.Z. Al-Ti-C master alloy with nano-sized TiC particles dispersed in the matrix prepared by using carbon nanotubes as C source. J. Alloys Compd. 2018, 748, 774-782. [CrossRef]

15. Ding, H.M.; Liu, X.F.; Yu, L. Influence of zirconium on grain refining efficiency of Al-Ti-C master alloys. J. Mater. Sci. 2007, 42, 9817-9821. [CrossRef]

16. Yang, H.B.; Qian, Z.; Zhang, H.N.; Nie, J.F.; Liu, X.F. The grain refinement performance of B-doped TiC on Zr-containing Al alloys. J. Alloys Compd. 2018, 731, 774-783. [CrossRef]

17. Ding, H.M.; Liu, X.F.; Yu, L.; Zhao, G.Q. The influence of the forming processes on the distribution and morphologies of TiC in Al-Ti-C master alloys. Scr. Mater. 2007, 57, 575-578. [CrossRef]

18. Liu, X.F.; Wang, Z.Q.; Zhang, Z.G.; Bian, X.F. The relationship between microstructures and refining performances of Al-Ti-C master alloys. Mater. Sci. Eng. A 2002, 332, 70-74. [CrossRef]

19. Yang, H.B.; Gao, T.; Wang, H.C.; Nie, J.F.; Liu, X.F. Influence of C/Ti stoichiometry in $\mathrm{TiC}_{\mathrm{x}}$ on the grain refinement efficiency of Al-Ti-C master alloy. J. Mater. Sci. Technol. 2017, 33, 616-622. [CrossRef]

20. Gezer, B.T.; Toptan, F.; Daglilar, S.; Kerti, I. Production of Al-Ti-C grain refiners with the addition of elemental carbon. Mater. Des. 2010, 31, S30-S35. [CrossRef]

21. Svynaarenko, K.; Zhang, Y.B.; Jie, J.C.; Kutsova, V.; Li, T.J. Microstructure and refinement performance of Al-Ti-C master alloy: Effect of excess Ti on the growth and nucleating ability of TiC particles. Met. Mater. Int. 2017, 5, 994-1001. [CrossRef]

22. Cho, Y.H.; Lee, J.M.; Kim, S.H. Al-TiC composites fabricated by a thermally activated reaction process in an Al melt using Al-Ti-C-CuO powder mixtures. Part I: Microstructure evolution and reaction mechanism. Metall. Mater. Trans. A 2017, 45, 5667-5678. [CrossRef]

23. Li, Y.X.; Hu, J.D.; Wang, H.Y.; Guo, Z.X.; Chumakov, A.N. Thermodynamic and lattice parameter calculation of $\mathrm{TiC}_{\mathrm{x}}$ produced from $\mathrm{Al}-\mathrm{Ti}-\mathrm{C}$ powders by laser igniting self-propagating high-temperature synthesis. Mater. Sci. Eng. A 2007, 458, 235-239. [CrossRef]

24. Li, P.J.; Kanndalova, E.G.; Ni, V.I. In situ synthesis of Al-TiC in aluminum melt. Mater. Lett. 2005, 59, 2545-2548. [CrossRef]

25. Wang, W.Q.; Liu, X.F.; Zhang, J.Y.; Bian, X.F. Reaction mechanism in an $\mathrm{Al}_{-} \mathrm{TiO}_{2}-\mathrm{C}$ system for producing in situ $\mathrm{Al} /\left(\mathrm{TiC}+\mathrm{Al}_{2} \mathrm{O}_{3}\right)$ composite. J. Mater. Sci. 2004, 39, 667-669. [CrossRef]

26. Crossly, F.A.; Mondolfo, L.F. Mechanism of grain refinement in aluminum alloys. J. Met. 1951, 12, 1143-1148. [CrossRef]

27. Wang, E.Z.; Gao, T.; Nie, J.F.; Liu, X.F. Grain refinement limit and mechanical properties of 6063 alloy inoculated by Al-Ti-C(B) master alloys. J. Alloys Compd. 2014, 594, 7-11. [CrossRef]

28. Birol, Y. Grain refining efficiency of Al-Ti-C alloys. J. Alloys Compd. 2006, 422, 128-131. [CrossRef]

29. Ju, Z.C.; Fan, N.; Ma, X.C.; Li, J.; Ma, X.J.; Xu, L.Q.; Qian, Y.T. Synthesis of uniform TiC hollow spheres by a Co-reduction route at low temperature. J. Phys. Chem. C 2007, 111, 16202-16206. [CrossRef]

30. Wu, X.Z.; Sun, T.; Wang, R.; Liu, L.L.; Liu, Q. Energy investigations on the adhesive properties of $\mathrm{Al} / \mathrm{TiC}$ interfaces: First-principles study. Phys. B Condens. Matter 2014, 449, 269-273. [CrossRef]

31. Ma, H.T.; Li, J.G.; Zhang, B.Q.; Fang, H.S. Research on crystal nuclei of aluminum alloy refined by Al-Ti-C master alloy. Heat Treat. Met. 1999, 10, 3-5.

32. Li, Y.L.; Chen, Y.B.; Cao, F.R.; Wen, J.L. Study on nucleation and attenuation mechanism of Al-Ti-C grain refiner. Spec. Cast. Nonferrous Alloys 2005, 25, 712-714.

33. Kattner, U.R.; Lin, J.C.; Chang, Y.A. Thermodynamic assessment and calculation of the Ti-Al system. Metall. Trans. A 1992, 23, 2081-2090. [CrossRef]

34. Arpón, R.; Narciso, J.; Louis, E.; García-Cordovilla, C. Interfacial reactions in Al/TiC particulate composites produced by pressure infiltration. Mater. Sci. Technol. 2003, 19, 1225-1230. [CrossRef]

35. Tronche, A.; Vandyoussefi, M.; Greer, A.L. Instability of TiC particles in aluminum melts inoculated with an Al-Ti-C grain refiner. Mater. Sci. Technol. 2002, 18, 1072-1078. [CrossRef]

36. Hou, Y.F. Structure Macro Kinetics of Combustion Synthesis Al-Ti-C and Grain Refining Performance Evaluation. Ph.D. Thesis, Lanzhou University of Technology, Lanzhou, China, 2007.

37. Dorward, R.C. Discussion of comments on the solubility of carbon in molten aluminium. Metall. Trans. A 1990, 21, 255-257. [CrossRef]

38. Banerji, A.; Reif, W. Metallographic investigation of TiC nucleants in the newly developed Al-Ti-C grain refiner. J. Mater. Sci. 1994, 29, 1958-1965. [CrossRef] 
39. Zhao, H.L.; Zhao, K.X.; Sun, Q.Y. Preparation and solidification process of Al-3Ti-0.2C-5Sr grain refiner. J. Zhengzhou Univ. Eng. Sci. 2015, 36, 14-17.

40. Kumar, G.S.; Murty, B.S.; Chakroabtry, M. Development of Al-Ti-C grain refiners and study of their grain refining efficiency on $\mathrm{Al}$ and Al-7Si alloy. J. Alloys Compd. 2005, 396, 143-150. [CrossRef]

41. Balog, M.; Florek, R.; Nosko, M.; Simancik, F. Self-Propagating Synthesis of Ti-Al-C Powder Mixtures. Key Eng. Mater. 2012, 520, 347-352. [CrossRef]

42. Witusiewicz, V.T.; Hallstedt, B.; Bondar, A.A.; Hecht, U.; Sleptsov, S.V.; Velikanova, T.Y. Thermodynamic description of the Al-C-Ti system. J. Alloys Compd. 2015, 623, 480-496. [CrossRef]

(C) 2020 by the authors. Licensee MDPI, Basel, Switzerland. This article is an open access article distributed under the terms and conditions of the Creative Commons Attribution (CC BY) license (http://creativecommons.org/licenses/by/4.0/). 